\title{
Un sistema de co-cultivo con células del cumulus oophurus mejora la calidad de embriones bovinos producidos in vitro
}

\author{
A co-culture system with cumulus oophurus cells improves the quality \\ of bovine embryos produced in vitro
}

\author{
Susana Guevara-Chacón ${ }^{1}$, Hurley Abel Quispe-Ccasa ${ }^{2,3}$, José Américo Saucedo- \\ Uriarte $^{2}$, Ilse Silvia Cayo-Colca ${ }^{1,2}$
}

\section{Resumen}

\begin{abstract}
El estudio tuvo como objetivo determinar la influencia de un sistema de co-cultivo con células del cumulus oophorus sobre la calidad de embriones bovinos producidos in vitro en función a su viabilidad. Se utilizaron ovarios de bovinos hembra cruzadas, sacrificadas en el Centro de Beneficio Municipal de Chachapoyas, Amazonas, Perú. Los ovocitos aspirados de folículos de 2-6 mm fueron madurados en medio TCM-199 por 24 horas, en una atmósfera humidificada con $6 \%$ de $\mathrm{CO}_{2}$ y a $38.5^{\circ} \mathrm{C}$. El estado de maduración fue determinado mediante el estadio nuclear a través de tinción acetoorceína. Los ovocitos maduros se fertilizaron in vitro con semen congelado de toros Angus durante 18 horas. Los presuntos cigotos fueron distribuidos aleatoriamente para su desarrollo en un grupo en medio con co-cultivo y otro en medio sin co-cultivo (control). Se determinó la calidad embrionaria en función a la actividad enzimática y daño al ADN de los embriones al séptimo día del cultivo, mediante los fluorocromos diacetato de fluoresceína (FDA) y yoduro de propidio (PI), respectivamente. No se encontró asociación significativa en la cantidad de embriones producidos in vitro, pero hubo diferencia significativa en viabilidad embrionaria a favor del sistema con co-cultivo $(\mathrm{p}<0.05)$. El uso de co-cultivos con células de cumulus oophurus mejora la viabilidad y, por lo tanto, la calidad embrionaria, sin influir en la tasa de producción de embriones in vitro.
\end{abstract}

Palabras clave: cumulus oophurus, fecundación in vitro, cultivo in vitro, viabilidad embrionaria, actividad enzimática

\footnotetext{
${ }^{1}$ Facultad de Ingeniería Zootecnista, Agronegocios y Biotecnología. Universidad Nacional Toribio Rodríguez de Mendoza de Amazonas, Perú

${ }^{2}$ Escuela de Posgrado, Universidad Nacional Toribio Rodríguez de Mendoza de Amazonas, Perú

${ }^{3}$ E-mail: hurleyabelqc@gmail.com
}

Recibido: 6 de noviembre de 2019

Aceptado para publicación: 23 de junio de 2020

Publicado: 11 de agosto de 2020 
The aim of this study was to determine the influence of a co-culture system with cumulus oophorus cells on the quality of bovine embryos produced in vitro, based on their viability. Ovaries from crossbred bovine slaughtered at the Chachapoyas Municipal Benefit Centre, Amazonas, Peru, were used. Oocytes aspirated from 2-6 mm follicles were matured in TCM-199 medium for 24 hours, in a humidified atmosphere with $6 \% \mathrm{CO}_{2}$ and $38.5^{\circ} \mathrm{C}$. The maturation state was determined by the nuclear stage through aceto-orcein staining. The mature oocytes were fertilized in vitro with frozen semen from Angus bulls for 18 hours. The presumed zygotes were randomly distributed for development in one group in medium with co-culture and another in medium without co-culture (control). The embryonic quality was determined based on the enzymatic activity and DNA damage of the embryos on the seventh day of culture, using the fluorochromes fluorescein diacetate (FDA) and propidium iodide (PI), respectively. No significant association was found in the number of embryos produced in vitro, but there was a significant difference in embryonic viability in favour of the system with co-culture $(\mathrm{p}<0.05)$. The use of co-cultures with cumulus oophurus cells improves viability and, therefore, embryonic quality, without influencing the rate of embryo production in vitro.

Key words: cumulus oophurus, in vitro fertilization, in vitro culture, embryonic viability, enzymatic activity

\section{INTRODUCCIÓN}

El desarrollo de nuevas biotecnologías para la obtención de líneas animales genéticamente superiores se basa en las técnicas de fecundación in vitro y cultivo de embriones. La producción de embriones in vitro es una herramienta valiosa para el desarrollo de la biotecnología, y los sistemas de co-cultivo son un complemento de esta tecnología, que se fundamenta en los procesos fisiológicos del desarrollo embrionario temprano que acontecen en los animales in vivo (Peláez, 2011).

La producción de embriones in vitro comprende tres pasos: la maduración de ovocitos in vitro obtenidos de la aspiración de folículos ováricos, la fecundación in vitro con gametos masculinos y, finalmente, el cultivo in vitro de embriones (Urrego et al., 2008). Cada uno de estos pasos involucran una serie de procesos fisiológicos relacionados entre sí, donde juega un papel importante la interacción que existe entre el óvulo y las células del cumulus oophurus (CCs) (Ferré y Cattaneo, 2013), para lograr la mayor tasa de ovocitos fertilizados y embriones viables. Los parámetros que miden la eficacia de la producción de embriones in vitro son la cantidad y calidad de los blastocistos que se logran (Ahuja et al., 2009).

La tasa de producción de embriones in vitro no ha variado en muchos años y la calidad de estos embriones continúa siendo inferior a la de los producidos in vivo, por diferencias morfológicas, funcionales y metabólicas, por alteraciones en expresión génica y por una mayor incidencia de apoptosis o muerte celular (Hirayama et al., 2014; Valleh et al., 2014). Para mejorar la calidad de los embriones se debe imitar las condiciones de un sistema in vivo, utilizando células que provengan de órganos donde naturalmente suceden estos eventos in vivo (Rexroad y Powell, 1988). El cumulus oophurus es un grupo de células que rodean al ovocito dentro del folículo ovárico y después de la ovulación, y son responsables de 
desarrollo de competencia y maduración (Marei et al., 2012). Un sistema de co-cultivo con células del cumulus es capaz de mejorar el medio de cultivo in vitro, permitiendo lograr estadios embrionarios avanzados como mórulas y blastocistos (Lorenzini, 1997).

Por ello, con el fin de mejorar los parámetros actuales de cantidad y calidad de embriones, el estudio tuvo como propósito determinar la influencia de un sistema de cocultivo con células del cumulus oophurus sobre la tasa y viabilidad de embriones bovinos producidos in vitro.

\section{Materiales y Métodos}

Todos los medios y reactivos utilizados fueron adquiridos de Sigma-Aldrich (St. Louis, USA), a menos que se especifique lo contrario.

\section{Ubicación del Estudio}

El estudio se llevó a cabo en el Laboratorio de Biotecnología Animal, Reproducción y Mejoramiento Genético de la Universidad Nacional Toribio Rodríguez de Mendoza de Amazonas, Perú. Los ovarios fueron colectados de hembras bovinas cruzadas (Bos taurus) sacrificadas en el Centro de Beneficio Municipal de Chachapoyas, región Amazonas, Perú, a una altitud de $2341 \mathrm{msnm}$.

\section{Aspiración y Selección de Células del Cumulus (CC)}

Los ovarios con presencia de cuerpo lúteo, cuerpo hemorrágico y presencia de folículo dominante fueron transportados al laboratorio en un recipiente isotérmico con solución salina de cloruro de sodio al $0.9 \% \mathrm{y}$ $0.0625 \mathrm{mg} / \mathrm{ml}$ de estreptomicina, temperado a $38^{\circ} \mathrm{C}$. Luego de un lavado en solución $\mathrm{NaCl}$ $0.9 \%$, se aspiraron los folículos de 2-6 mm de diámetro (Raghu et al., 2002), con una aguja $\left.18 \mathrm{G} 1 \frac{1}{2}\right\rangle$ y jeringa de $10 \mathrm{ml}$ cargada con medio PBS-PVA ( $8 \mathrm{~g}$ de $\mathrm{KCl}, 0.2 \mathrm{~g}$ de
$\mathrm{NaCl}, 2.9 \mathrm{~g}$ de $\mathrm{Na}_{2} \mathrm{HPO}_{4}, 0.2 \mathrm{~g}$ de $\mathrm{KH}_{2} \mathrm{PO}_{4}$, $1 \mathrm{~g}$ de PVA en $1 \mathrm{~L}$ de agua) suplementado con $0.01 \mathrm{mg} / \mathrm{ml}$ de gentamicina. La búsqueda y selección de los COCs se realizó en estereoscopio (Olympus, Japón) con el mismo medio de aspiración y temperado a $37{ }^{\circ} \mathrm{C}$. Se seleccionaron COCs con ovocitos de más de cuatro capas de células del cúmulus y citoplasma homogéneo (Categoría A), y con una a tres capas de células del cúmulus y citoplasma homogéneo (categoría B) (Senatore et al., 2010).

\section{Aislamiento y Cultivo de COCs}

Las células del cumulus oophurus (CC) se obtuvieron al momento de la aspiración folicular, ya que estas se desprenden de los COC. Estas células fueron aisladas y cultivadas en una placa de $60 \mathrm{~mm}$, dentro de gotas de $100 \mu 1$ del medio de cultivo que contenían medio SOF base modificado $(0.6294 \mathrm{~g}$ de $\mathrm{NaCl}, 0.0534 \mathrm{~g}$ de $\mathrm{KCl}, 0.0162 \mathrm{~g}$ de $\mathrm{KH}_{2} \mathrm{PO}_{4}, 0.2106 \mathrm{~g}$ de $\mathrm{NaHCO}_{3}, 0.018 \mathrm{~g}$ de $\mathrm{CaCl}_{2} 2 \mathrm{H}_{2} \mathrm{O}, 0.00996 \mathrm{~g}$ de $\mathrm{MgCl}_{2} 6 \mathrm{H}_{2} \mathrm{O}, 3.3$ g de Na-piruvato, $47 \mu 1$ de Na-Lactato, 0.0146 $\mathrm{g}$ de L-glutamina, $0.0080 \mathrm{~g}$ de kanamicina, $0.0002 \mathrm{~g}$ de rojo fenol, $0.3 \mathrm{~g}$ de BSA y $100 \mathrm{ml}$ de agua), suplementado con $1 \mathrm{X}$ de aminoácidos esenciales, $1 \mathrm{X}$ de aminoácidos no esenciales y $0.04 \mathrm{mg} / \mathrm{ml}$ de mioinositol. Las gotas se cubrieron de aceite mineral y se incubaron en atmosfera humidificada a $38.5{ }^{\circ} \mathrm{C}$ y con $6 \%$ de $\mathrm{CO}_{2}$ durante 42 horas (Kubo et al., 2015).

\section{Maduración in vitro}

Se obtuvieron $800 \mathrm{COCs}$, que fueron sometidos a maduración en medio TCM-199 suplementado con $0.5 \mathrm{mg} / \mathrm{ml}$ de piruvato de sodio, $12 \mu \mathrm{g} / \mathrm{ml}$ de EGF (Factor de Crecimiento Epidermal), $0.05 \mathrm{UI} / \mathrm{ml}$ de FSH (Hormona Folículo Estimulante), $0.05 \mathrm{UI} / \mathrm{ml}$ de LH (Hormona Luteinizante), $0.004 \mathrm{UI} / \mathrm{ml}$ de $\mathrm{HMG}$ (Gonadotrofina Menopáusica Humana) y $10 \%$ de SFB (Suero Fetal Bovino), en placas de $35 \mathrm{~mm}$ (Nunc, USA) dentro de una incubadora (ESCO, Singapur) con $6 \%$ de $\mathrm{CO}_{2}$ a 


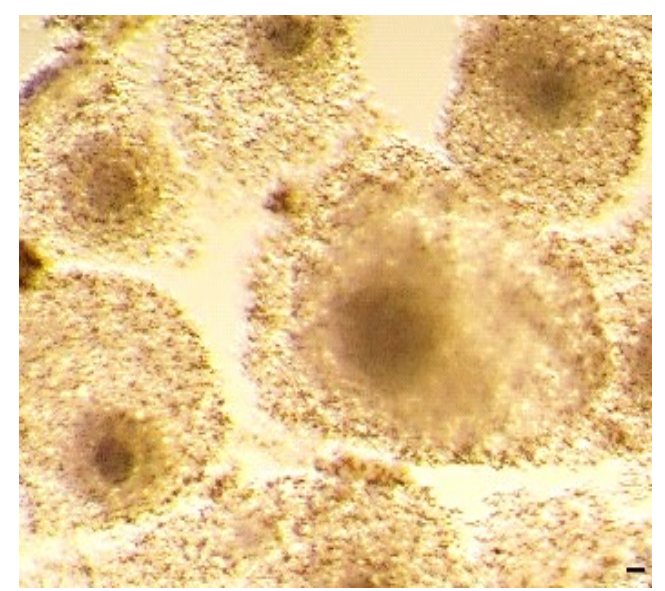

Figura 1. Expansión de células del cumulus oophorus de los complejos ovocito-cumulus (COCs) luego de 24 horas de maduración in vitro. La barra indica $50 \mu \mathrm{m}$

$38.5^{\circ} \mathrm{C}$, durante 24 horas (Figura 1). Luego de la incubación, los ovocitos fueron clasificados como maduros o en metafase II, por la presencia del corpúsculo polar, cromosomas condensados y ausencia de vesícula germinal. Para ello, $10 \%$ de ovocitos maduros seleccionados al azar y denudados, fueron fijados en placas portaobjetos y sumergidos parcialmente en solución de ácido acético-etanol (1:3, vol/vol). Luego de 72 horas como mínimo, fueron teñidos con $1 \%$ de solución acetoorceina (wt/vol) (Motlik y Fulka, 1976) y se evaluó la estructura nuclear en un microscopio binocular (Olympus, Japón) con objetivo de 40X.

\section{Fecundación y Cultivo in vitro}

Se utilizó semen congelado en pajillas de toros Angus con fertilidad comprobada. Se seleccionaron los espermatozoides de mayor motilidad mediante gradiente de Percoll (Parrish et al., 1995) en una centrifuga (BOECO, Alemania), y capacitados en medio SOF base modificado previamente descrito, suplementado con $0.24 \mu \mathrm{g} / \mathrm{ml}$ de heparina. Los COCs madurados y los espermatozoides capacitados se incubaron en gotas de $75 \mu 1$ del medio SOF base modificado dentro de placas de $35 \mathrm{~mm}$, en una atmósfera humidificada a $38.5^{\circ} \mathrm{C}$ con $6 \% \mathrm{CO}_{2}$, durante 18 horas.

Los presuntos cigotos fueron denudados y lavados en el medio SOF base modificado suplementado con $1 \mathrm{X}$ de aminoácidos esenciales, $1 \mathrm{X}$ de aminoácidos no esenciales y $0.04 \mathrm{mg} / \mathrm{ml}$ de mioinositol. Luego, 310 cigotos confirmados con dos células como mínimo, fueron distribuidos a los dos grupos de cultivo in vitro. Los cigotos del grupo de cultivo con sistema de co-cultivo fueron cultivados en grupos de 25 , dentro de gotas de $100 \mu 1$ de medio, cubiertas con aceite mineral y en placas de $60 \mathrm{~mm}$. Los cigotos del grupo control se cultivaron en grupos de 25 , dentro de gotas de $75 \mu 1$ de medio, cubiertas de aceite mineral y en placas de $35 \mathrm{~mm}$. Ambos grupos fueron sometidos a atmósfera humidificada a $38.5^{\circ} \mathrm{C}$ con $6 \%$ de $\mathrm{CO}_{2}$.

\section{Viabilidad Embrionaria}

Se estimó la calidad embrionaria a través de la tinción con yoduro de propidio (PI) y diacetato de fluoresceína (FDA), ya que esta combinación de fluorocromos indica el daño al ADN y la actividad enzimática, respectivamente. Para ello, los embriones en estadio de mórula y blastocisto fueron denudados manualmente con micropipeta de 200 $\mu 1$, en medio de manipulación PBS-PVA suplementado con $0.025 \mathrm{mg} / \mathrm{ml}$ de estreptomicina. Luego, se colocaron en medio de tinción compuesto por PBS-PVA suplementado con $0.1 \mathrm{mg} / \mathrm{ml} \mathrm{de} \mathrm{PI} \mathrm{y} 0.0015 \mathrm{mg} / \mathrm{ml} \mathrm{de}$ FDA e incubados por 10 minutos. Finalmente, los embriones fueron evaluados en microscopio invertido con fluorescencia (Olympus, Japón), donde la coloración verde brillante indicó actividad enzimática y viabilidad, verde oscuro indicó daño celular y baja actividad enzimática, y coloración roja muerte celular y daño en el ADN (Figura 2). La intensidad de la coloración fue medida con el programa Adobe Photoshop CC 2014. 
Cuadro 1. Estadio nuclear de complejos ovocito-cumulus (COCs) a las 24 horas de maduración in vitro

\begin{tabular}{ccc}
\hline \multirow{2}{*}{$\begin{array}{c}\text { Ovocitos } \\
\mathrm{n}(\%)\end{array}$} & \multicolumn{2}{c}{ Estadio nuclear } \\
\cline { 2 - 3 } & $\begin{array}{c}\mathrm{MII}^{1} \\
\mathrm{n}(\%)\end{array}$ & $\begin{array}{c}\text { Degenerados } \\
\mathrm{n}(\%)\end{array}$ \\
\hline $80(100)$ & $60(75)$ & $20(25)$ \\
\hline
\end{tabular}

${ }^{1}$ MII: ovocito maduro en metafase II

\section{Análisis Estadístico}

Se determinó la asociación del sistema de co-cultivo con la producción de cigotos y la viabilidad embrionaria mediante la prueba de Chi-cuadrado, con un nivel de confianza del 95\%, en el programa Statistix 8.0.

\section{Resultados y Discusión}

Previa a la maduración in vitro, 30 ovocitos de las categorías A y B fueron teñidos con aceto-orceína, observándose que $86.7 \%$ de ovocitos se encontraban en estadio nuclear de vesícula germinal. Este porcentaje indica que la clasificación y selección se realizó adecuadamente para un proceso de maduración; sin embargo, 13.3\% correspondió a ovocitos degenerados a pesar de que los COC fueron categorizados como A y B. Senatore et al. (2010) determinaron que COCs de categorías A y B poseen mayor capacidad de maduración y fecundación, pudiendo llegar a producir blastocistos, mientras que COC de categoría $\mathrm{C}$ y $\mathrm{D}$ no tienen la capacidad de maduración.

El 75\% de los COCs alcanzó la metafase de la segunda división meiótica (metafase II) luego de 24 horas de incubación, mientras que el restante $25 \%$ de ovocitos degeneraron sin llegar a madurar (Cuadro 1). Sin embargo, cabe resaltar que según la evaluación de vesícula germinal previa a la maduración in vitro, un porcentaje de COC categorizados como A y B ya estarían degenerados, incluso antes de ingresar al proceso de maduración. Además, todos los ovocitos presentaron expansión de células de cumulus al final de la maduración in vitro, pero solo los que culminaron el periodo de maduración presentaron la extrusión del primer corpúsculo polar. Esta tasa de maduración in vitro es superior al $61.4 \%$ reportado por Francisco et al. (2008) e inferior al $90 \%$ reportado por Soto-Martínez et al. (2019). Estas diferencias podrían atribuirse al tamaño de los folículos ováricos aspirados, al protocolo de maduración y a las características de los animales empleados en cada estudio. Van den Hurk y Zhao (2005) señalan que las células del cumulus son fundamentales para el desarrollo embrionario, ya que conectadas al citoplasma del ovocito mediante uniones gap durante la maduración, transportan nutrientes, precursores metabólicos y hormonas esenciales para la maduración del ovocito.

Después de la fertilización in vitro, los 310 cigotos que fueron seleccionados exhibían extrusión de pronúcleos masculino y femenino, así como la primera división (dos células). Mucci et al. (2006) sostienen que solo el $80 \%$ de ovocitos podrá ser fecundado y continuar dividiéndose a 2 y 4 células. Luego de siete días de cultivo, la prueba de viabilidad con FDA evidenció diferencias significativas $(\mathrm{p}<0.05)$ y mayor actividad enzimática en embriones sometidos a un sistema con cocultivo $(51 \pm 58)$, respecto a embriones sin co-cultivo $(27 \pm 26)$. Además, la tinción con PI evidenció menor daño a nivel del ADN en embriones del sistema con co-cultivo (Figura 2). Esta adición podría estar sincronizando la división nuclear y citoplasmática, así como previniendo el endurecimiento de la zona pelucida para facilitar la eclosión del blastocisto (Dey et al., 2012). 

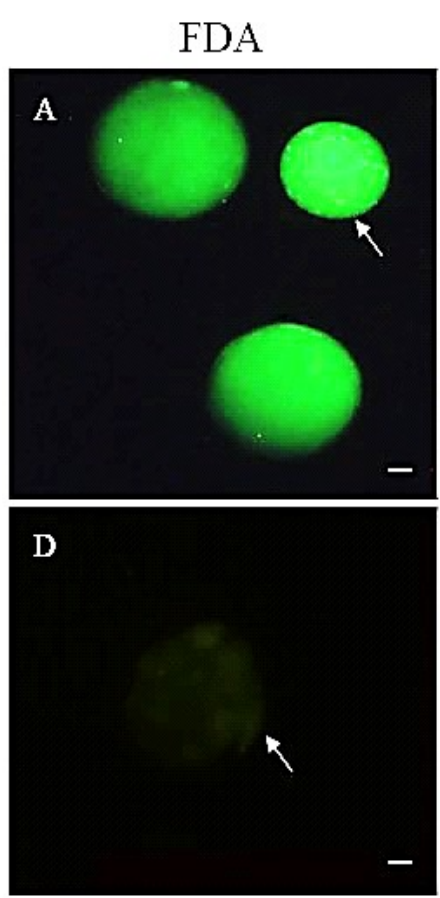

PI

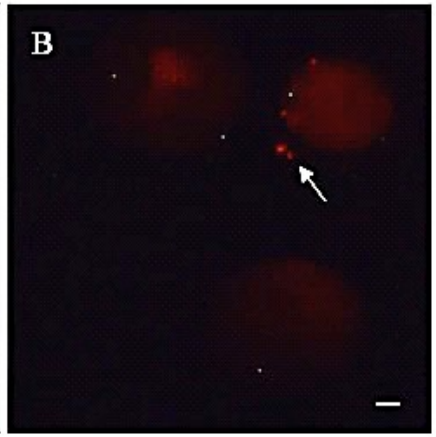

$\mathrm{E}$

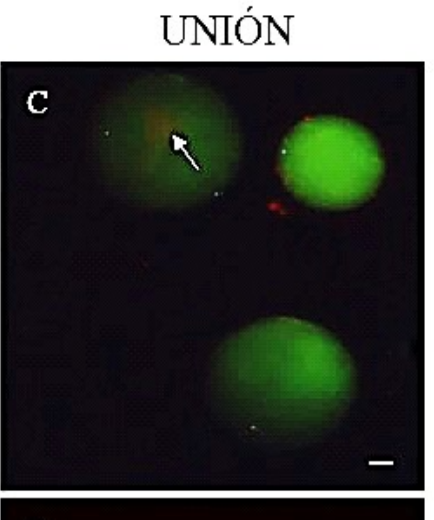

$\mathbf{F}$

Figura 2. Viabilidad de embriones bovinos a los siete días de cultivo, mediante fluorescencia y tinción con yoduro de propidio (PI) y diacetato de fluoresceína (FDA). A: blastocisto viable (color verde brillante indica actividad enzimática-viabilidad), B: blastocisto con trazas de muerte celular (probablemente de células del cumulus), D: blastocisto no viable (color verde obscuro indica bajo nivel de actividad enzimática), E: blastocisto con muerte celular (color rojo brillante indica daño al ADN). La barra indica $50 \mu \mathrm{m}$

No se encontró diferencia significativa en el porcentaje de embriones viables entre ambos sistemas de cultivo in vitro, aunque aparentemente el sistema sin co-cultivo podría tener un proceso de desarrollo más acelerado que el sistema con co-cultivo. En el Cuadro 2 se aprecia el estadio embrionario alcanzado al séptimo día de cultivo in vitro, donde las tasas de mórula, blastocisto inicial, blastocisto propiamente dicho y blastocisto expandido, así como el porcentaje de degenerados, son similares entre ambos sistemas de cultivo y no existe asociación entre el sistema de co-cultivo y la cantidad de estructuras encontradas $(p>0.05)$. Estos hallazgos discrepan del estudio de Cordova et al. (2014), quienes sostienen que el co-cultivo con células epiteliales mejora la tasa de de- sarrollo embrionario bovino, pero coincide en que se mejora su calidad.

Resultados inferiores han sido reportados por Goovaerts et al. (2009), con 6.3\% de blastocistos en un sistema de co-cultivo con células del cumulus y un ambiente con mezcla de gases. No obstante, se debe considerar que en este estudio solo se usó $\mathrm{CO}_{2}$, de modo que el sistema de cultivo en gotas, así como los medios y periodo de cultivo pudieron influir en el proceso. Sin embargo, aunque en este estudio se observó que el sistema de co-cultivo con células del cúmulus podría estar retardando el desarrollo embrionario, pero a su vez podría influir en la sincronización de los eventos durante el ciclo celular, mejorando la calidad de los embriones pro- 
Cuadro 2. Estadios de desarrollo in vitro de embriones bovinos hasta los siete días, según sistema de co-cultivo

\begin{tabular}{lcccccc}
\hline $\begin{array}{l}\text { Sistema de } \\
\text { cultivo in vitro }\end{array}$ & $\mathrm{n}$ & $\begin{array}{c}\text { Degenerado } \\
\mathrm{n}(\%)\end{array}$ & $\begin{array}{c}\text { Mórula } \\
\mathrm{n}(\%)\end{array}$ & $\begin{array}{c}\text { Blastocisto } \\
\text { inicial } \\
\mathrm{n}(\%)\end{array}$ & $\begin{array}{c}\text { Blastocisto } \\
\mathrm{n}(\%)\end{array}$ & $\begin{array}{c}\text { Blastocisto } \\
\text { expandido } \\
\mathrm{n}(\%)\end{array}$ \\
\hline sin co-cultivo & 155 & $77(48.9)^{\mathrm{a}}$ & $31(20.4)^{\mathrm{a}}$ & $34(22.0)^{\mathrm{a}}$ & $11(7.3)^{\mathrm{a}}$ & $2(1.4)^{\mathrm{a}}$ \\
con co-cultivo & 155 & $73(46.6)^{\mathrm{a}}$ & $39(25.7)^{\mathrm{a}}$ & $32(20.6)^{\mathrm{a}}$ & $8(5.0)^{\mathrm{a}}$ & $3(2.1)^{\mathrm{a}}$ \\
\hline
\end{tabular}

${ }^{a}$ Letras iguales dentro de columnas indican diferencias no significativas $(p>0.05)$

El co-cultivo se realizó con células del cumulus oophurus

ducidos (Senatore et al., 2010). Las células del cumulus cumplen funciones importantes para el soporte nutricional de los ovocitos, secretan hormonas esteroideas e inducen la reacción acrosomal de los espermatozoides (Canipari, 1994; Mattioli et al., 1998).

La producción de embriones in vitro genera bajas tasas de blastocistos (5-30\%), consecuencia del bloqueo del desarrollo por la manipulación del óvulo o del embrión. Para evitar ello, se han empleado co-cultivos con células somáticas, células de cumulus, células del epitelio oviductal, obteniendo resultados controversiales (Reed et al., 1996; Bousquet et al., 1999; Soto-Martínez et al., 2019). Staigmiller y Moor (1984) y Kamishita et al. (1999) observaron que en co-cultivos con células del cumulus y células epiteliales, respectivamente, se incrementó la capacidad de desarrollo del embrión. Las células del cumulus parecen tener propiedades embriotróficas, las cuales en el medio de cultivo pueden ser responsables del efecto benéfico del co-cultivo para los embriones (Mulheron y Schomberg, 1992; Vansteenbrugge et al., 1994). Sin embargo, en este estudio, el uso de co-cultivo no difirió del grupo control (sin co-cultivo) respecto a la tasa de embriones producidos in vitro, probablemente por el protocolo empleado o fuente de células somáticas.

\section{Conclusiones}

- Si bien la calidad de los ovocitos está determinada por el número de células de cumulus que componen el complejos ovocito-cumulus (COC), la morfología y el color, esta no es determinante para la competencia al momento de la maduración, ya que una proporción de COCs de categorías A y B podría encontrarse en proceso de degeneración.

- Las tasas de mórulas y blastocistos bovinos producidos in vitro fueron estadísticamente similares entre los sistemas de cultivo con y sin co-cultivo. Sin embargo, el uso de co-cultivos con células de cumulus oophurus permitió mejorar su viabilidad, evidenciada por mayor actividad enzimática y por lo tanto, una mejor calidad para continuar su desarrollo.

\section{Literatura Citada}

1. Ahuja C, Montiel F, Pérez P, Gallegos J. 2009. Medio alternativo para la producción in vitro de embriones bovinos. Zootec Trop 27: 277-284. 
2. Bousquet D, Twagiramungu H, Morin $N$, Brisson C, Carboneau G, Durocher J. 1999. In vitro embryo production in the cow: an effective alternative to the conventional embryo production approach. Theriogenology 51: 59-70. doi: 10.1016/s0093-691x(98)00231-3

3. Canipari R. 1994. Cell-cell interactions and oocyte growth. Zygote 2: 343-345. doi: 10.1017/S0967199400002173

4. Cordova A, Perreau C, Uzbekova S, Ponsart C, Locatelli Y, Mermillo P. 2014. Development rate and gene expression of IVP bovine embryos cocultured with bovine oviduct epithelial cells at early or late stage of preimplantation development. Theriogenology 81 : 1163-1173. doi: 10.1016/j.theriogenology.2014.01.012

5. Dey S, Deb G, Ha A, Lee J, Bang J, Lee K, Kong I. 2012. Coculturing denuded oocytes during the in vitro maturation of bovine cumulus oocytes complexes exerts a synergistic effect on embryo development. Theriogenology 77 : 1064-1077. doi: 10.1016/j.theriogenology.2011.10.009

6. Ferré L, Cattaneo L. 2013. Biotecnologías reproductivas: producción in vitro de embriones y semen sexado. Rev Med Vet (B Aires) 94: 28-36.

7. Francisco JBC, Ludwing H, Patricia CVM. 2008. Estudio estructural del huso meiótico de ovocitos bovinos vitrificados. Rev Cient (Maracaibo) 18: 253-261.

8. Goovaerts J, Leroy J, Van Soom A, De Cleorcq J, Andries S, Bols P. 2009. Effect of cumulus cell cocultured on oxygen tension on the in vitro developmental competence of bovine zygotes cultured singly. Theriogenology 71: 729738. doi: $10.1016 / \mathrm{j}$.theriogenology.2008.09.038

9. Hirayama H, Moriyasu S, Kageyama S, Sawai K, Takahashi H, Geshi M, Fujii T, et al. 2014. Enhancement of maternal recognition of pregnancy with parthenogenetic embryos in bovine embryo transfer. Theriogenology 81 : 1108-1115. doi: 10.1016/j.theriogenology.2014.01.039

10. Kamishita H, Takagi M, Choi YH, Wijayagunawardane MPB, Miyazawa K, Sato K. 1999. Development of in vitro matured and fertilized bovine embryos cocultured with bovine oviductal epithelial cells obtained from oviducts ipsilateral to cystic follicles. Anim Reprod Sci 56: 201-209. doi: 10.1016/s03784320(99)00046-9

11. Kubo N, Cayo-Colca IS, Mijano T. 2015. Effect of estradiol-17 $\beta$ during in vitro growth culture on the growth, maturation, cumulus expansion and development of porcine oocytes from early antral follicles. Anim Sci J 86: 251259. doi: 10.1111/asj.12283

12. Lorenzini EJ. 1997. Desarrollo de embriones bovinos obtenidos de ovocitos madurados in vitro bajo diferentes condiciones de cultivo. Tesis de Médico Veterinario. Valdivia, Chile: Univ. Austral de Chile. 52 p.

13. Marei W, Ghafaric F, Fouladi-Nashta A. 2012. Role of hyaluronic acid in maturation and further early embryo development of bovine oocytes. Theriogenology 78: 670-677. doi: 10.1016/ j.theriogenology.2012.03.013

14. Mattioli M, Lucidi P, Barboni B. 1998. Expanded cumuli induce acrosome reaction in boar sperm. Mol Reprod Dev 51: 445-453. doi: 10.1002/(SICI)10982795 (199812) $51: 4<445::$ A ID MRD12>3.0.CO;2-L

15. Motlik J, Fulka J. 1976. Breakdown of the germinal vesicle in pig oocytes in vivo and in vitro. J Exp Zool 198: 155162. doi: 10.1002/jez.1401980205

16. Mucci N, Aller J, Kaiser G, Hozbor F, Alberio R. 2006. Producción in vitro de embriones bovinos: suplementación de los medios de cultivo con suero. Arch Med Vet 38: 97-104. doi: 10.4067/S0301732X2006000200002 
17. Mulheron GW, Schomberg DW. 1992. Effects of diethylstilbestrol on rat granulosa cell and theca/interstitial cell transforming growth factor-beta2 mRNA expression in vivo: analysis by reverse transcription-polymerase chain reaction. Biol Reprod 46: 546-550. doi: 10.1095/biolreprod46.4.546

18. Parrish JJ, Krogenaes A, SuskoParrish JL. 1995. Effect of bovine sperm separation by swim up or percoll on success of in vitro fertilization and embryo development. Theriogenology 44: 859-870. doi: 10.1016/0093-691X(95)00271-9

19. Peláez V. 2011. Producción in vitro de embriones bovinos. Tesis de Médico Veterinario. Cuenca, Ecuador: Univ. de Cuenca. $86 \mathrm{p}$.

20. Raghu HM, Nandi S, Reddy S. 2002. Follicle size and oocyte diameter in relation to developmental competence of buffalo oocytes in vitro. Reprod Fertil Dev 14: 55-61. doi: 10.1071/rd01060

21. Reed WA, Suh TK, Bunch TD, White $K L$. 1996. Culture of in vitro fertilized bovine embryos with bovine oviductal epithelial cells, buffalo rat liver (BRL) cells, or BRL-cell-conditioned medium. Theriogenology 45: 439-449. doi: 10.1016/0093-691x(95)00380-q

22. Rexroad CE, Powell AM. 1988. Coculture of ovine eggs with oviductal cells and trophoblastics vesicles. Theriogenology 29: 387-397. doi: 10.1016/0093691X(88)90242-7

23. Senatore E, Xu J, Suárez M, Gong G, Lin T, Bella A, Moreno J, Mannino $M$, et al. 2010. Improved in vitro development of OPU-derived bovine (Bos taurus) embryos by group culture with agarose-embedded helper embryos.
Theriogenology 74: 1643-1651. doi: 10.1016/j.theriogenology.2010.06.037

24. Soto-Martínez YG, Casas-Hernández E, Betancourt-Rule JM, FernándezReyes F. 2019. Desarrollo embrionario bovino in vitro co-cultivado con células oviductales y del cumulus oophorus. Rev Salud Anim 41(1). [Internet]. Disponible en: http://scielo.sld.cu/pdf/rsa/ v41n1/2224-4700-rsa-41-01-e01.pdf

25. Staigmiller RB, Moor RM. 1984. Effect of follicle cells on the maturation and developmental competence of ovine oocytes maturated outside the follicle. Gamete Res 9: 221-229. doi: 10.1002/ mrd.1120090211

26. Urrego R, Tarazona A, Olivera $M$, Camargo O. 2008. Simplificación de la fertilización de ovocitos durante la producción in vitro de embriones bovinos. Rev Colomb Cienc Pec 21: 398-405.

27. Valleh MV, Hyttel P, Aabech M, Strobech L. 2014. Insulin-like growth factor 2: a modulator of anti-apoptosis related genes (HSP70, BCL2-L1) in bovine preimplantation embryos. Theriogenology 82: 942-950. doi: 10.1016/ j.theriogenology.2014.07.003

28. Van den Hurk R, Zhao J. 2005. Formation of mammalian oocytes and their growth, differentiation and maturation within ovarian follicles. Theriogenology 63: 1717-1751. doi: 10.1016/ j.theriogenology.2004.08.005

29. Vansteenbrugge A, Van Langendonckt A, Scutenaire C, Massip A, Dessy F. 1994. In vitro development of bovine embryos in buffalo rat liver-or bovine oviduct conditioned medium. Theriogenology 42: 931-940. doi: 10.1016/0093691x(94)90116-z 